Article

\title{
Application of Graphene-Oxide-Modified Polyacrylate Polymer for Controlled-Release Coated Urea
}

\author{
Wenjun Yuan, Yazhen Shen, Fei Ma and Changwen Du * (D) \\ State Key Laboratory of Soil and Sustainable Agriculture, Institute of Soil Science, Chinese Academy of Sciences, \\ Nanjing 210008, China; wjyuan@issas.ac.cn (W.Y.); yzshen@issas.ac.cn (Y.S.); fma@issas.ac.cn (F.M.) \\ * Correspondence: chwdu@issas.ac.cn; Tel.: +86-25-8688-1565
}

Received: 18 December 2017; Accepted: 5 February 2018; Published: 8 February 2018

\begin{abstract}
Polyacrylate polymer (PA) was modified with graphene oxide (GO) and the obtained composites were applied as coatings for controlled-release coated urea (CRU). The physicochemical properties of the different PA/GO coatings were characterized in detail and the nitrogen-release characteristics of the obtained CRU samples were determined in water at $25^{\circ} \mathrm{C}$. The experimental results revealed that addition of GO to PA reduced the swelling degree from $83.01 \%$ to $46.35 \%$ and improved its mechanical properties (the Young's modulus was improved from 31.52 to $34.97 \mathrm{MPa}$ and the glass transition temperature was increased from 4.21 to $6.11^{\circ} \mathrm{C}$ ), thus dramatically slowing down the cumulative nutrient release from the CRU fertilizer from $87.25 \%$ to $59.71 \%$. These results suggest that GO enhances the properties of PA for CRU applications, which shows that GO-modified PA is a good coating material.
\end{abstract}

Keywords: polyacrylate polymer; graphene oxide; controlled-release coated urea; physical blending method

\section{Introduction}

With the rapid population growth, the demand for grain production has raised significantly. In order to satisfy the food needs of our ever-growing population, the development of modern mechanical agriculture techniques and the extensive use of chemical fertilizers and pesticides are key. Fan and Pardey [1] have suggested that $21.7 \%$ of the agriculture production growth in China from 1965 to 1993 resulted from the increasing use of fertilizers. Nitrogen is an essential element for sustainable crop growth, playing a very important role in food safety. However, a series of environmental problems have arisen owing to its high loss susceptibility via (a) volatilization in the form of ammonia which contributes to the greenhouse effect; (b) leaching in the form of nitrates which leads to the eutrophication of waterbody; (c) runoff, and other possible forms [2]. The total fertilizer consumption is expected to increase to 208 million tons by 2020 [3], however, assimilation of fertilizer nitrogen by plants is approximately $50 \%$ on average [4-7]. Because of the low use efficiency of $\mathrm{N}$ and the maximum use of nitrogen fertilizer, the use of urea poses a dilemma. To increase the efficient use of urea and minimize its negative impact on the environment, controlled-release fertilizers have been proposed as one of the solutions $[8,9]$.

In recent years, with the gradual emergence of new materials, more research is focusing on the application of new materials for the controlled release of fertilizers using coating materials [10-13]. Due to the excellent film-forming properties, low price and appropriate viscosity [14,15], waterborne polyacrylate does not influence the soil structure or activities of soil microorganisms [16], which (polyacrylate polymer, PA, Figure 1) has attracted much attention from the scientific community. However, PA still needs to be modified to obtain better release performances owing to its poor water resistance and film strength; 
in addition, the viscosity of waterborne PA is highly influenced by the temperature [17]. Thus, it is important to further improve the hydrophobicity and mechanical properties of such PA polymers. A potentially effective way to solve this problem is to modify PA through graphene oxide.

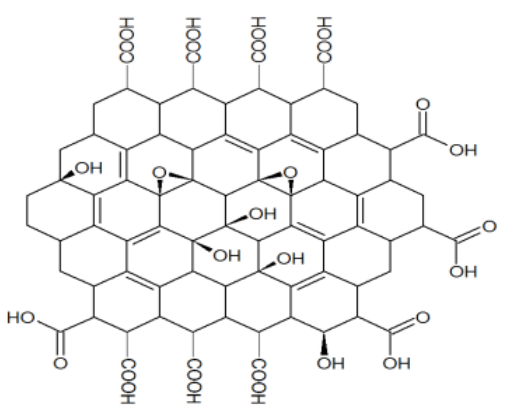

(a)<smiles>CCOC(=O)C(C)CCC(C)(CC(C)C(=O)O)C(=O)OC</smiles>

(b)

Figure 1. Chemical structures of (a) graphene oxide and (b) PA.

Graphene, a molecular sheet of graphite, is a two-dimensional one-atom-thick carbon sheet with a planar honeycomb lattice, which was first successfully separated from graphite by Geim and Novoselov [18] through a mechanical stripping method. Graphene has attracted great attention from scientists since 2004 [18], whose extraordinary physicochemical properties [19-22] (e.g., high surface area, excellent electrical conductivity, strong mechanical strength, unparalleled thermal conductivity) make it promising nanoscale filler for the fabrication of polymer composites.

Owing to its high surface area and surface energy, graphene is not easily dispersed in solution. The most reproducible approach for the preparation of graphene-based polymer composites is by employing graphene oxide (GO) as the precursor (Figure 1). In contrast to pristine graphene, plenty of oxygen-containing groups exist on the GO surface [23,24]. These functional groups not only allow for good dispersion of GO in aqueous solution, but also facilitate the interactions between the host polymer and GO via covalent and/or noncovalent bonding [25-27]. By taking advantage of GO, several GO-water-soluble polymer composites with noticeably improved properties have been obtained [28-30].

In an extension to our previous studies, we have successfully prepared waterborne PA/GO composites by a physical blending method $[31,32]$ with the aim of achieving improved nutrient release from fertilizers. In this article, PA was modified with different amounts of GO to form cross-linking networks, improving the physicochemical properties of PA, which were then applied as coating materials to delay the nutrient release cycle of fertilizers.

\section{Materials and Methods}

\subsection{Materials}

A single-layer GO dispersion (single layer ratio $>80 \%, 0.5-5$ microns of lateral size, average surface area of 700-800 $\mathrm{m}^{2} / \mathrm{g}, 7.0-7.5$ at.\% oxygen) was obtained from Nanjing XFNANO Materials Tech Co., Ltd. (Nanjing, China). Methyl methacrylate (MMA, AR), n-butyl acrylate (BA, CP), and methacrylic acid (MAA, $\mathrm{CP})$ were purchased from Nanjing Chemical Regent Co., Ltd. (Nanjing, China). Sodium dodecylbenzene sulfonate (SDBS, AR) was supplied by Chengdu Kelong Chemical Reagent Co., Ltd. (Chengdu, China). Nonyl-phenyl-polyoxyethylene ether-10 (OP-10, CP) was received from Nanjing Chemical Regent Co., Ltd., and potassium persulfate (KPS, CP) from Sinopharm Chemical Regent Co., Ltd. (Shanghai, Country). Granular urea with 2-3 nm of diameter (LP) was provided by Shandong Luxi Fertilizer Co., Ltd. (Liaocheng, China). 


\subsection{Synthesis of Polyacrylate Polymer}

PA was synthesized by a semicontinuous emulsion polymerization method, as shown in Figure 2. The aqueous phase was prepared by placing $8.24 \mathrm{~g}$ of OP-10 and $4.12 \mathrm{~g}$ of SDBS in a $500 \mathrm{~mL}$ glass bottle, which were then completely dissolved in $250 \mathrm{~mL}$ deionized water to form a foamy mixture; this mixture was finally transferred to a $1000 \mathrm{~mL}$ dried three-necked flask. The organic phase was prepared by mixing $110 \mathrm{~g}$ of BA, $90 \mathrm{~g}$ of MMA, and $3.5 \mathrm{~g}$ of MAA. Then, the two phases were mixed and stirred together for $30 \mathrm{~min}$ in the three-necked flask. Around 75\% (by mass) of the oil-water mixture was separated for further use. The remaining $25 \%$ (by mass) of the oil-water mixture in the three-necked flask was used as the initial solution, whose temperature was raised to $80{ }^{\circ} \mathrm{C}$. The remaining $75 \%$ of the oil-water mixture and the initiator solution ( $\left.12 \mathrm{~g}, 0.01 \mathrm{~g} \cdot \mathrm{L}^{-1} \mathrm{KPS}\right)$ were added alternately in four doses over $3 \mathrm{~h}$, and the polymerization reaction was carried out under air atmosphere for another $3 \mathrm{~h}$. The solid content of the emulsion was $40 \%$.

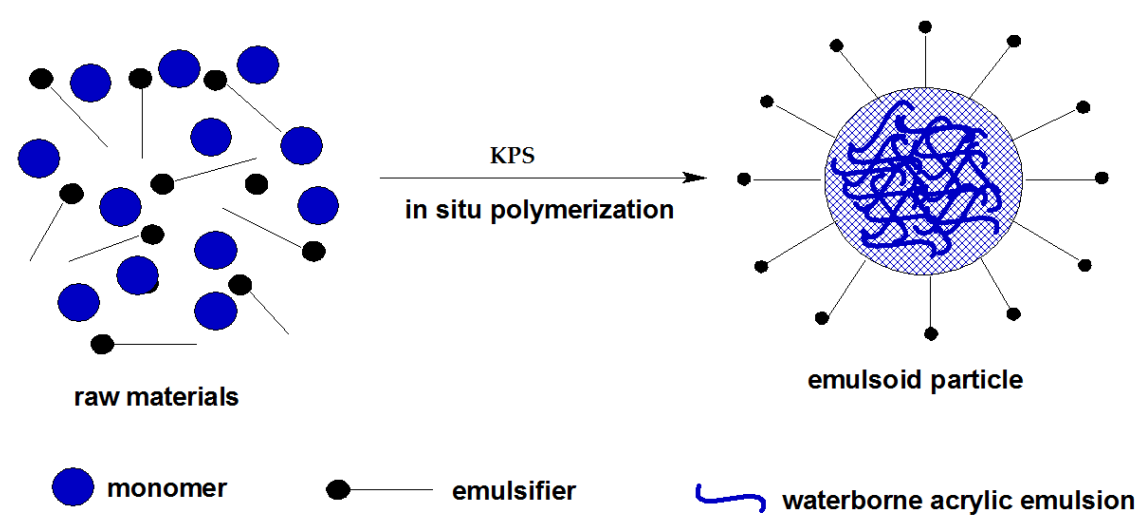

Figure 2. Synthesis of polyacrylate polymer.

\subsection{Fabrication of PA/GO Composites and Preparation of Film Samples}

Different composites were prepared by a physical blending method. Given amounts of a GO solution and PA were mixed in a $500 \mathrm{~mL}$ flask and the obtained reaction mixture was stirred for $30 \mathrm{~min}$ under $1000 \mathrm{rpm}$ stirring. The above blends were then homogenized using 600 bars six times to obtain homogeneous emulsions, as shown in Figure 3.

Film samples were prepared by casting the prepared emulsions $(250 \mathrm{~g})$ on glass dishes with diameter of $15 \mathrm{~cm}$, which were then dried in an oven at $60{ }^{\circ} \mathrm{C}$ for $72 \mathrm{~h}$. The film samples were then removed from the glass dishes for future use.

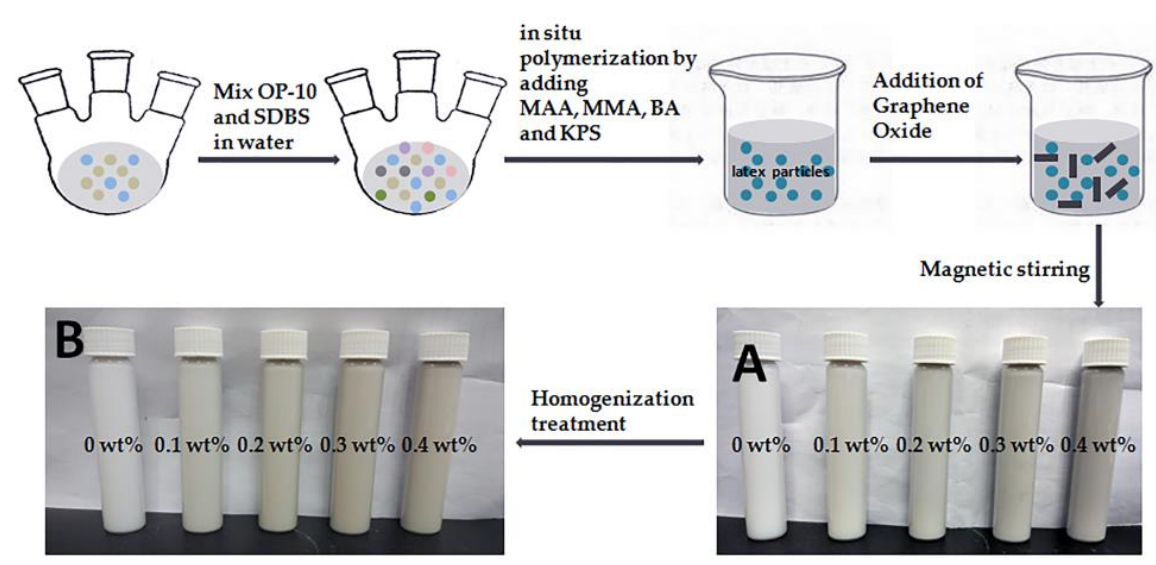

Figure 3. Procedure to prepare the PA/GO composites: (A) the emulsions with magnetic stirring; picture; (B) the emulsions with homogenization treatment. 


\subsection{Characterization of the Film Samples}

An FTIR (Fourier Transform infrared spectroscopy) spectrometer (Nicolet 6700, Waltham, MA, USA) equipped with photoacoustic accessory (Model 300, MTEC, Des Moines, IA, USA) (FTIR-PAS) was used for the determination of the spectra of CRU (controlled-release coated urea) coated with pure polyacrylate and modified polyacrylate. The spectra were recorded in the wavenumber range of $650-4000 \mathrm{~cm}^{-1}$ with two different mirror velocities: $0.32 \mathrm{~cm} \cdot \mathrm{s}^{-1}$ and $0.64 \mathrm{~cm} \cdot \mathrm{s}^{-1}$, and 32 successive scans were conducted with a resolution of $4 \mathrm{~cm}^{-1}$. Black carbon was used as a reference.

Tensile measurements were performed with universal material testing machine (Instron 3366, Boston, MA, USA) at room temperature of $24{ }^{\circ} \mathrm{C}$ and $53 \%$ relative humidity with crosshead speed was $200 \mathrm{~mm} \cdot \mathrm{min}^{-1}$.

The degree of swelling is defined as [33]:

$$
\frac{W_{2}-W_{1}}{W_{1}} \times 100 \%
$$

The film samples were immersed into $50 \mathrm{~mL}$ deionized water at $25^{\circ} \mathrm{C}$ in the wide mouth bottle of $50 \mathrm{~mL}$, the mass of film samples before $\left(w_{1}\right)$ and after $\left(w_{2}\right)$ immersion were recorded. The samples were weighed every three days until the weight was constant.

The glass transition temperature was evaluated by differential scanning calorimeters (Pyris 1 DSC, Perkin-Elmer, Waltham, MA, USA), which was made at heating rate of $20^{\circ} \mathrm{C} \cdot \mathrm{min}^{-1}$. The thermal behavior for the films were examined under the nitrogen atmosphere between $-50-100{ }^{\circ} \mathrm{C}$.

\subsection{Preparation of Controlled-Release Coated Urea}

The fertilizer granules were coated in a Wurster fluidized bed equipped with a bottom-spray pneumatic nozzle (LDP-3, Changzhou Zhiyang Machinery Equipment Co., Ltd., Changzhou, China). The process parameters were as follows: fluidized bed temperature of $30-50{ }^{\circ} \mathrm{C}$, emulsion spray rate of $2.5 \mathrm{~g} \cdot \mathrm{min}^{-1}$, and atomization pressure of $0.1 \mathrm{MPa}$. The amount of emulsion was $98.28 \mathrm{~g}$ per $400 \mathrm{~g}$ of the original fertilizer granules. In all cases, the coated pellets were tray-dried in an oven at $60^{\circ} \mathrm{C}$ for $72 \mathrm{~h}$ before use.

\subsection{Nitrogen Release Characteristic of Controlled-Release Coated Urea}

The release process for the controlled-release coated urea (CRU) can be divided into the following stages [9]: (1) water (mainly vapor) penetration; (2) dissolution in the solid core; and (3) pressure build-up and/or swelling (in the alkyd type only). There are two pathways in the third stage: "failure" release if rupture occurs or "diffusion" release. To determine the release characteristics of CRU, $5 \mathrm{~g}$ of the coated fertilizer was immersed in $100 \mathrm{~mL}$ of deionized water at $25{ }^{\circ} \mathrm{C}$ in an incubator. The coated fertilizers were ground to determine the content of residual nutrient in the 1,3,5, 7, 10, 14, 28 days [34]. The release characteristics were estimated as the cumulative release percentage versus time, after which the nitrogen release was over $80 \%$. The urea solution $(100 \mathrm{~mL})$ was removed periodically and replaced with $100 \mathrm{~mL}$ of deionized water. The experiments were carried out in triplicate. The nitrogen concentration was evaluated by the p-dimethylaminobenzaldehyde colorimetric method (Epoch 2, Microplate Spectrophotometer, BioTek, Winooski, VT, USA). The release profiles were estimated as the cumulative dissolution versus time.

\section{Results and Discussion}

\subsection{Synthesis of PA/GO Composites}

Figure 3 illustrates the detailed synthetic process of PA/GO composites via the covalent interactions formed during the physical blending of $\mathrm{GO}$ and the water acrylic emulsions, where magnetic stirring and homogenizing treatments were included to ensure the uniform dispersion of GO and PA. 
As shown in Figure 3, the solution obtained by magnetic stirring through this physical blending method was denoted dispersion 1 (Figure 3A). After magnetic stirring, a homogenization treatment was applied to obtain dispersion 2 (Figure 3B). By comparing the two different dispersions, one can easily observe the differences in color with the increasing amount of GO. Moreover, the dispersion 1 samples appear brighter and more delicate than the dispersion 2 samples.

As shown in the Figure 3, with the increase of the amount of graphene oxide, which could easily see the difference in color when the amount of $0.4 \mathrm{wt} \%$ graphene oxide was added; dispersion 1 appeared more bright and delicate in contrast with the dispersion 2.

\subsection{Characterizations of the Film Samples}

\subsubsection{The Swelling Degree of the Film Samples}

Experiments to determine the swelling degree were carried out to investigate the hydrophobicity of the film samples: lower swelling degrees indicate better water resistance [35]. The water swelling degree of the film samples is shown in Figure 4. Compared to $0 \mathrm{wt} \%$, the swelling degree was significantly reduced after modification with GO. Upon addition of GO, the oxygen-containing functional groups in the surface of GO easily interact with PA to form a cross-linking networks structure that reduces the swelling, inducing such a big difference between the 0 and $0.1 \mathrm{wt} \%$ treatments [36,37]. With the increasing amount of GO, in general, the swelling degree displays first a rising trend to then decrease. From 0.1 to $0.3 \mathrm{wt} \%$ GO, the swelling degree increases, indicating poor water resistance, owing to the strong van der Waals attraction forces between adjacent layers, which induce GO to bundle together forming aggregates and eventually result in an increase of the swelling. At a GO content of $0.3 \mathrm{wt} \%$, the swelling degree no longer increases. With the increasing amount of GO from 0.3 to $0.4 \mathrm{wt} \%$, the number of network connections in the film samples increases gradually until reaching the equilibrium, and thus the swelling degree of the film decreases.

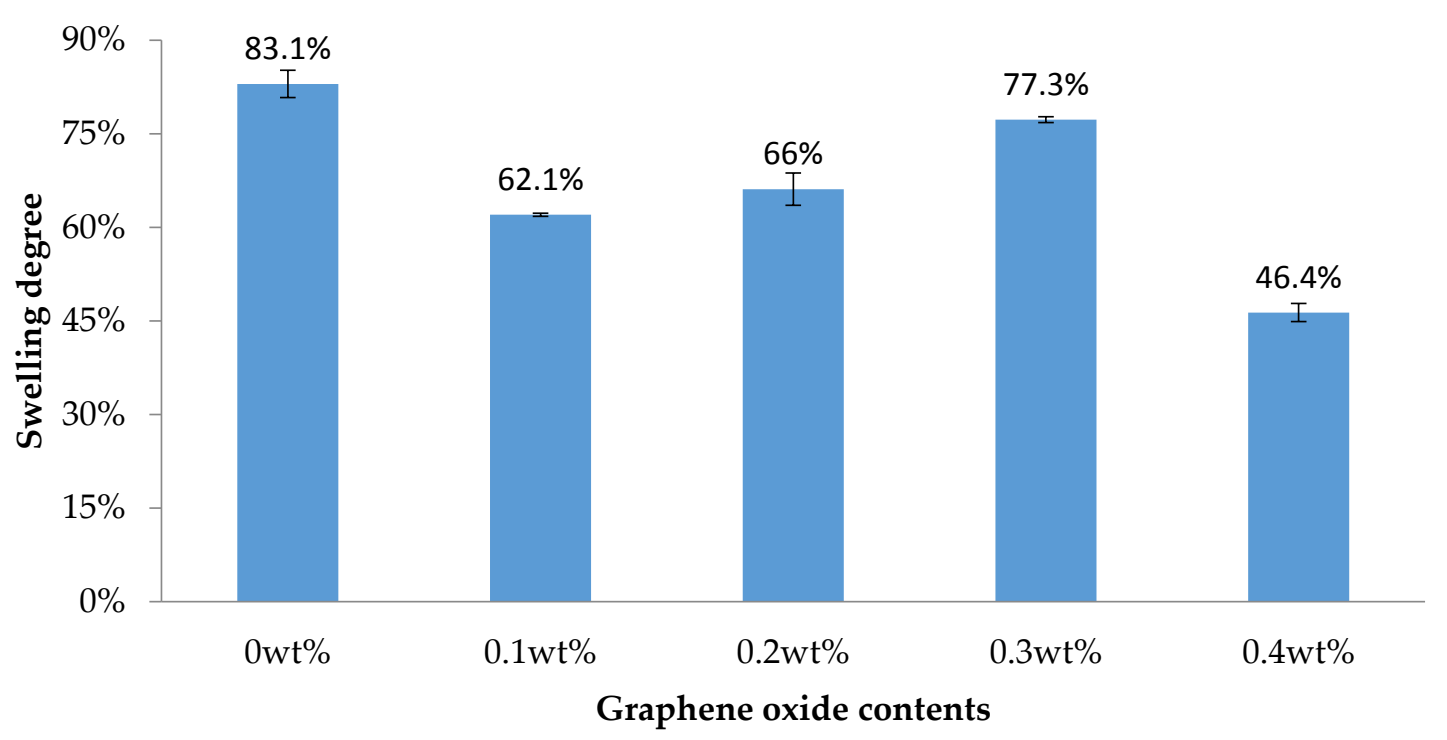

Figure 4. The swelling degrees of film samples prepared with different graphene oxide contents.

\subsubsection{The Glass Transition Temperature of Film Samples}

The glass transition temperature $\left(T_{\mathrm{g}}\right)$ is a function of the chain flexibility. DSC analysis was preformed to investigate the influence of the GO content on the thermal behavior of polyacrylate emulsions. Low $T_{\mathrm{g}}$ values cause the fertilizer particles to easily stick together, thus affecting the packing of the fertilizer. If the $T_{\mathrm{g}}$ is too high, the coating is vulnerable to breakage and sudden fracture [38]. 
The glass transition temperature of the film samples were obtained from the DSC data. From Table 1, the difference in $T_{\mathrm{g}}$ of the GO modified polyacrylate films probably resulted from the higher degree of crosslinking reaction, which restricted the PA molecular movement [39]. From 0.1 to $0.3 \mathrm{wt} \%$, the slightly decrease in $T_{\mathrm{g}}$ is probably because the functional groups of $\mathrm{GO}$ initiated cyclization at lower temperature by an ionic mechanism [40]. With the increasing GO content from 0.3 to $0.4 \mathrm{wt} \%$, the GO layers become more compact, hindering the mobility of the polymer segments and reducing the plastic deformation of the polymer.

Table 1. The glass transition temperature $\left(T_{\mathrm{g}}\right)$ and physical properties of composites.

\begin{tabular}{ccccc}
\hline $\begin{array}{c}\text { GO Content } \\
(\mathbf{w t} \mathbf{\%})\end{array}$ & $\mathbf{T}_{\mathbf{g}}\left({ }^{\circ} \mathbf{C}\right)$ & $\begin{array}{c}\text { Stress at Break } \\
\mathbf{( M P a )}\end{array}$ & $\begin{array}{c}\text { Strain at Break } \\
\mathbf{( \% )}\end{array}$ & $\begin{array}{c}\text { Young's Modulus } \\
\mathbf{( M P a )}\end{array}$ \\
\hline 0 & 4.21 & $4.88 \pm 0.57$ & $814.5 \pm 24.6$ & $31.52 \pm 4.65$ \\
0.1 & 5.77 & $3.66 \pm 0.41$ & $742.8 \pm 37.3$ & $33.94 \pm 1.85$ \\
0.2 & 5.80 & $3.68 \pm 0.29$ & $753.9 \pm 29.8$ & $34.76 \pm 3.44$ \\
0.3 & 5.43 & $4.03 \pm 0.40$ & $724.2 \pm 46.8$ & $27.42 \pm 3.83$ \\
0.4 & 6.11 & $5.57 \pm 0.39$ & $911.5 \pm 14.1$ & $34.97 \pm 1.02$ \\
\hline
\end{tabular}

\subsubsection{Mechanical Properties}

Tensile testing was carried out to characterize the effect of the GO content on the mechanical properties of PA. For accuracy, five duplicate samples were measured at $24{ }^{\circ} \mathrm{C}$ and relative humidity of $53 \%$ and the obtained values were averaged.

The average stress at break, strain at break, and Young's modulus are listed in Table 1. It can be seen that the strength and modulus of pure PA are smaller than those of the GO-modified PA samples. The additions of $0.4 \mathrm{wt} \% \mathrm{GO}$ increased the modulus from 31.52 to $34.97 \mathrm{MPa}$, the stress at break from 4.88 to $5.57 \mathrm{MPa}$, and the strain at break from $814.5 \%$ to $911.5 \%$. Such a significant improvement can be attributed to the layered structure of the GO surface. Based on the above results, it can be speculated that, in the PA/GO composites, GO provides anchoring sites to link the water acrylic emulsion chains via cross-linking reaction.

\subsubsection{FTIR-PAS Analysis}

FTIR analysis was conducted to investigate the interactions between GO and PA. Figure 5 shows the FTIR-PAS spectra of the different model films at different moving-mirror rates.

In the spectra, the band at $2950 \mathrm{~cm}^{-1}$ is ascribed to the aliphatic $\mathrm{C}-\mathrm{H}$ stretch vibration, that at $2349 \mathrm{~cm}^{-1}$ to the $\mathrm{C}=\mathrm{O}$ bond vibration (arising from the carbon dioxide in the background air), the band at $1730 \mathrm{~cm}^{-1}$ to the carboxyl $\mathrm{C}=\mathrm{O}$ stretch vibration, the absorption band at $1450 \mathrm{~cm}^{-1}$ corresponds to the aliphatic hydrocarbon $\mathrm{C}-\mathrm{H}$ deformation vibration, the absorption peak at $1160 \mathrm{~cm}^{-1}$ to the ester C-O stretch vibration, and the absorption bands at $900-990 \mathrm{~cm}^{-1}$ are ascribed to the lipid skeleton C-C stretch vibrations (see Table 2). These results confirm that the composites were successfully prepared.

In Figure 5, aliphatic characteristic peaks generally indicate the hydrophobic of the films, while carboxyl groups generally means the strong hydrophilicity of the films [41]. When the rate of moving mirror was $0.16 \mathrm{~cm} \cdot \mathrm{s}^{-1}$, the characteristic peaks of aliphatic group and carboxyl group were high. When the moving mirror velocity was $0.32 \mathrm{~cm} \cdot \mathrm{s}^{-1}$, the number of hydrophilic and water-absorbing groups decreased obviously. These variations confirmed the existence of cross-linking networks between the oxygen groups of GO and PA. The relative absorption intensity of the absorption bands varies obviously with the GO content, indicating changes in the membrane structure. Such spectra support the existence of strong interactions between $\mathrm{GO}$ and the water acrylic emulsions. 


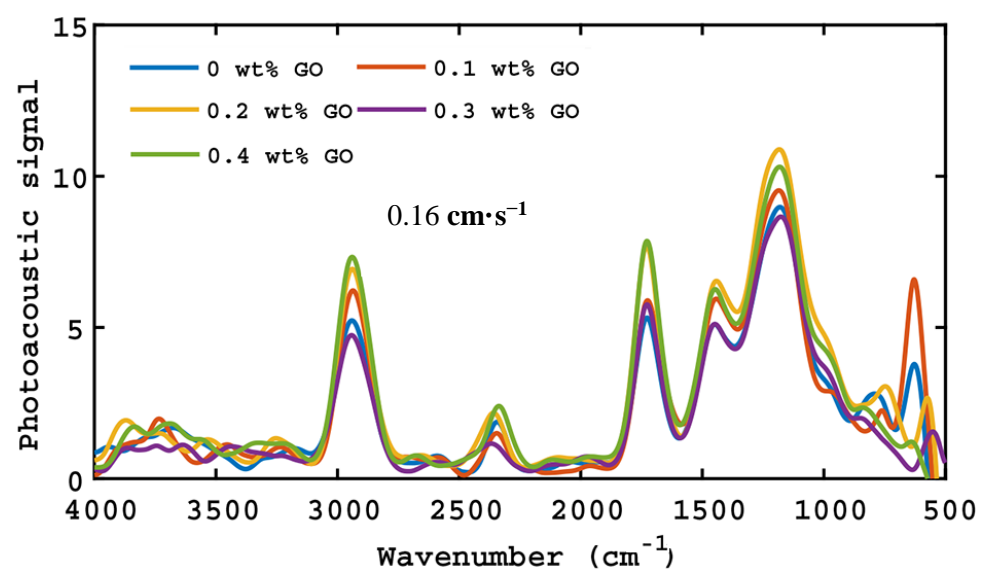

(a)

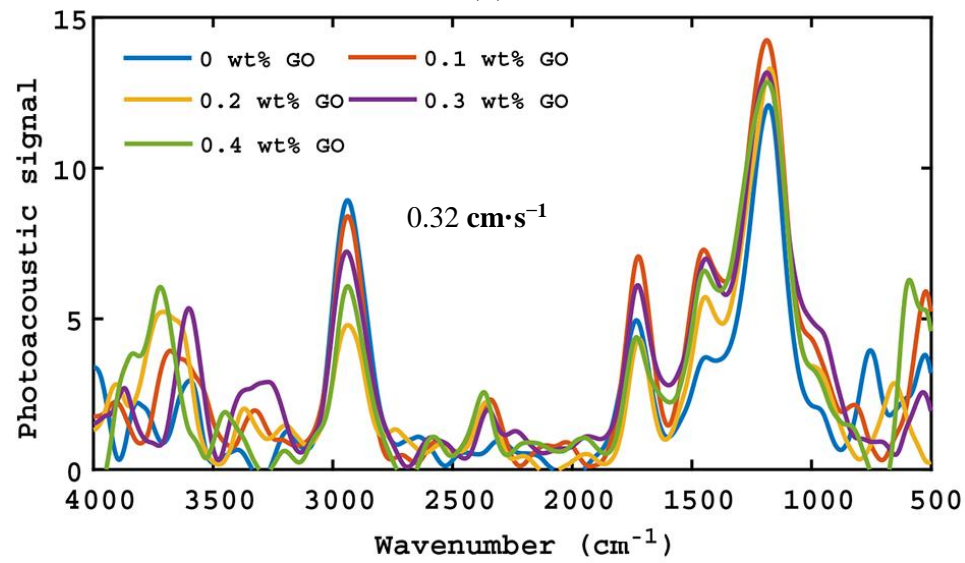

(b)

Figure 5. FTIR-PAS spectra of the film samples: (a) Infrared spectrum with a moving mirror velocity of $0.16 \mathrm{~cm} \cdot \mathrm{s}^{-1} ;(\mathbf{b})$ Infrared spectrum with a moving mirror velocity of $0.32 \mathrm{~cm} \cdot \mathrm{s}^{-1}$.

Table 2. Assignments of main absorbance bands.

\begin{tabular}{cc}
\hline Wavenumber $\left(\mathbf{c m}^{-\mathbf{1}}\right)$ & Assignment \\
\hline 2950 & $\mathrm{C}-\mathrm{H}$ stretching $\left(-\mathrm{CH}_{3}\right)$ \\
2349 & $\mathrm{C}=\mathrm{O}$ symmetrical stretching $\left(\mathrm{CO}_{2}\right)$ \\
1730 & $\mathrm{C}=\mathrm{O}$ stretching $(\mathrm{COOR})$ \\
1450 & $\mathrm{C}-\mathrm{H}$ deformation $\left(-\mathrm{CH}_{3},-\mathrm{CH}_{2}{ }^{-}\right)$ \\
1160 & $\mathrm{C}-\mathrm{O}-\mathrm{C}$ stretching $(-\mathrm{COOR})$ \\
$900-990$ & $\mathrm{C}-\mathrm{C}$ stretch(lipid skeleton) \\
\hline
\end{tabular}

\subsection{Nutrient Release Behavior of CRU}

The controlled-release behavior, evaluated by the hydrostatic digestion method, is one of the most significant features of coated fertilizers. It can be used to select the optimum amount of GO for the PA coatings for CRU. Figure 6 shows the nutrient release curves of PA composites modified with different amounts of GO. Compared to CRU with pure PA ( $0.0 \mathrm{wt} \% \mathrm{GO})$, all the CRU samples coated with PA/GO show a significant slower nitrogen release throughout the 28-day experiment. With the increasing GO content, the nutrient release rate of the coated urea increased first and then decreased. The amount of nitrogen released in the initial $24 \mathrm{~h}$ was $7.58 \%, 6.60 \%, 8.03 \%, 9.47 \%$, and $8.74 \%$ for the $0,0.1,0.2,0.3$ and $0.4 \mathrm{wt} \%$ PA/GO samples, respectively, and $87.25 \%, 69.35 \%, 78 \%, 77.68 \%, 59.71 \%$ after 28 days, respectively. Owing to the excellent mechanical properties of $\mathrm{GO}$, its use as a reinforcing agent delays the nutrient release rate. 
With the increasing GO content, the cumulative nutrient release rate starts to decline due to the strong van Edward forces in GO [23], which facilitate the aggregation of GO. After precipitation in the emulsion owing to severe agglomeration, the dispersion of the emulsion becomes difficult, thereby affecting the performance of the controlled-release coated fertilizer. From $0.3 \mathrm{wt} \%$ to $0.4 \mathrm{wt} \% \mathrm{GO}$, the total release of nitrogen drops sharply. The interactions between PA and GO increase greatly by intermolecular intertwining, thus hampering the movement of the PA matrix molecular chains. This in turn improves the hydrophobicity, strength, ductility, toughness, and other mechanical properties of the coating, and prolongs the CRU cycle. After 28 days, the $0.4 \mathrm{wt} \%$ PA/GO-CRU sample exhibited a cumulative nutrient release of $59.71 \%$, significantly lower than the $87.25 \%$ obtained for the CRU coated with pure PA. Therefore, it can be concluded that the release cycle of the coated fertilizer was elongated.

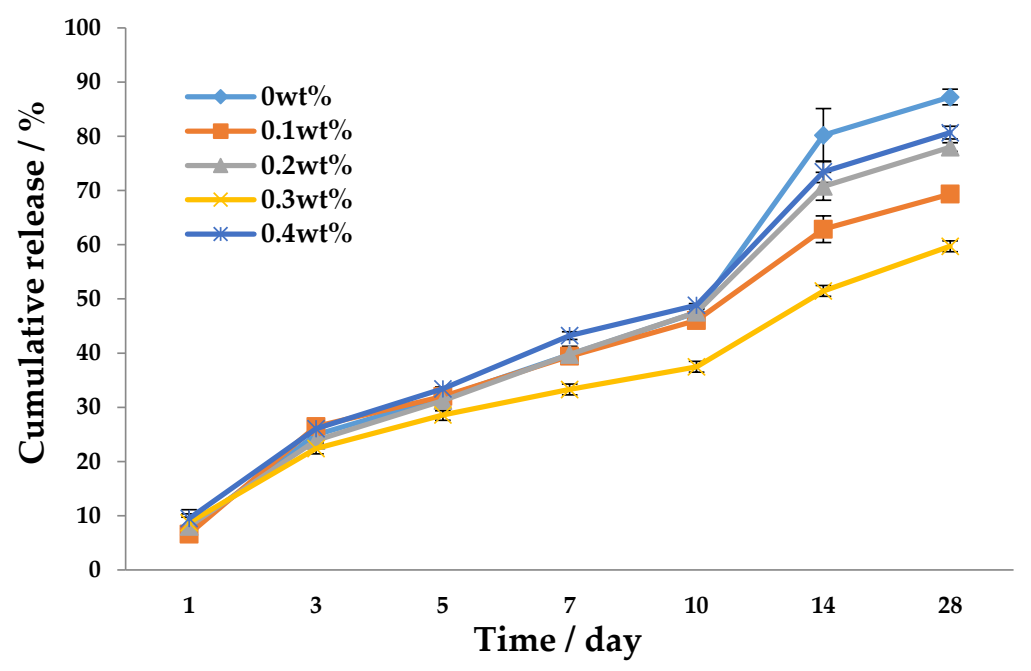

Figure 6. The cumulative release curves of graphene oxide modified polyacrylate polymer coated urea in water at $25^{\circ} \mathrm{C}$.

\section{Conclusions}

In this work, waterborne polyacrylate polymer was successfully modified with graphene oxide through a physical blending method. Compared to the fertilizer coated with pure waterborne polyacrylate polymer, the graphene oxide-modified polyacrylate polymer samples exhibited better performance as coating materials for controlled-release fertilizers, with a clear water resistance enhancement, resulting from the formation of a cross-linking network between graphene oxide and polyacrylate polymer. In addition, the mechanical properties of the film were greatly improved and the nutrient release was slowed down, e.g., the 28 -day cumulative nutrient release was reduced from $87.25 \%$ to $59.71 \%$. Overall, our findings show that simple blending of graphene oxide with polyacrylate polymer produced an excellent coating for delaying urea release when the amount of graphene oxide is $0.3 \mathrm{wt} \%$, improving coating strength and weakening the tackiness. Waterborne polyacrylate polymer, particularly after graphene oxide modification, has therefore great potential in waterborne polymer-coated controlled-release fertilizer industry.

Acknowledgments: The authors wish to thank the following for their financial support: the National Key Research and Development Program of China (Grant No. 2017YFD0200704), and the Key Research and Development Program of Jiangsu province (BE2017388).

Author Contributions: Wenjun Yuan performed the experiments, analyzed the data and wrote the first draft. Yazhen Shen and Fei Ma provided materials and involved in data analysis. Changwen Du supervised the whole study and prepared the final manuscript.

Conflicts of Interest: The authors declare no conflicts of interest. 


\section{References}

1. Fan, S.; Pardey, P.G. Research, productivity, and output growth in Chinese agriculture. J. Dev. Econ. 1997, 53, 115-137. [CrossRef]

2. Zhu, Z.; Chen, D. Nitrogen fertilizer use in China-Contributions to food production, impacts on the environment and best management strategies. Nutr. Cycl. Agroecosyst. 2002, 63, 117-127. [CrossRef]

3. Heffer, P.; Prud'homme, M. Fertilizer Outlook 2017-2021. In Proceedings of the 85th IFA Annual Conference, Marrakech, Morocco, 22-24 May 2017.

4. Mosier, A.R.; Syers, J.K.; Freney, J.R. Nitrogen fertilizer: An essential component of food, feed, and fiber production. In Agriculture and the Nitrogen Cycle: Assessing the Impacts of Fertilizer Use on Food Production and the Environment; Island Press: St. Louis, MO, USA, 2004.

5. Van Cleemput, O.; Zapata, F.; Vanlauwe, B. Use of Tracer Technology in Mineral Fertilizer Management. In Guidelines on Nitrogen Management in Agricultural Systems; IAEA: Vienna, Austria, 2008; pp. 19-125.

6. Dobermann, A. Nitrogen use efficiency-State of the art. In Proceedings of the IFA International Workshop on Enhanced-Efficiency Fertilizers, Frankfurt, Germany, 28-30 June 2005.

7. Smil, V.A. Nitrogen in crop production: An account of global flows. Glob. Biogeochem. Cycles 1999, 3, 647-662. [CrossRef]

8. Mikkelsen, R.L. Using hydrophilic polymers to improve uptake of manganese fertilizers by soybeans. Nutr. Cycl. Agroecosyst. 1995, 41, 87-92. [CrossRef]

9. Yan, X. Recent Advances on the technologies to increase fertilizer use efficiency. J. Intergr. Agric. 2008, 7, 469-479. [CrossRef]

10. Majeed, Z.; Ramli, N.K.; Mansor, N.; Man, Z. A comprehensive review on biodegradable polymers and their blends used in controlled-release fertilizer processes. Rev. Chem. Eng. 2015, 31, 69-96. [CrossRef]

11. Shaviv, A. Advances in controlled-release fertilizers. Adv. Agron. 2001, 71, 1-49.

12. Treinyte, J.; Grazuleviciene, V.; Paleckiene, R.; Ostrauskaite, J.; Cesoniene, L. Biodegradable Polymer Composites as Coating Materials for Granular Fertilizers. J. Polym. Environ. 2017, in press. [CrossRef]

13. Zhang, F.-D.; Wang, Y.-J. Current situation and development trend of slow/controlled release fertilizer in China. Soil Fertil. Sci. Chin. 2008, 26, 1-4. (In Chinese)

14. Da Rosa, S.G.; dos Santos Rocha, S.C. Effect of process conditions on particle growth for spouted bed coating of urea. Chem. Eng. Process. Process Intensif. 2010, 49, 836-842. [CrossRef]

15. Donida, M.W.; Rocha, S.C.S. Coating of urea with an aqueous polymeric suspension ion a two-dimensional spouted bed. Dry. Technol. 2002, 20, 685-704. [CrossRef]

16. Zhou, Z.; Du, C.; Li, T.; Shen, Y.; Zeng, Y.; Du, J.; Zhou, J. Biodegradation of a biochar-modified waterborne polyacrylate membrane coating for controlled-release fertilizer and its effects on soil bacterial community profiles. Environ. Sci. Pollut. Res. 2015, 22, 8672-8682. [CrossRef] [PubMed]

17. Shen, Y.; Zhao, Z.; Zhou, J.; Du, C. Application of waterborne acrylicemulsions in coated controlled release fertilizer using reacted layer technology. Chin. J. Chem. Eng. 2015, 23, 309-314. [CrossRef]

18. Geim, A.K.; Novoselov, K.S. The rise of graphene. Nat. Mater. 2007, 6, 183-191. [CrossRef] [PubMed]

19. Sengupta, R.; Bhattacharya, M.; Bandyopadhyay, S.; Bhowmick, A.K. A review on the mechanical and electrical properties of graphite and modified graphite reinforced polymer composites. Prog. Polym. Sci. 2011, 36, 638-670. [CrossRef]

20. Bolotin, K.I.; Sikes, K.J.; Jiang, Z.; Klima, M.; Fudenberg, G.; Hone, J.; Kim, P.; Stormer, H.L. Ultrahigh electron mobility in suspended graphene. Solid State Commun. 2008, 146, 351-355. [CrossRef]

21. Suk, J.W.; Piner, R.D.; An, J.; Ruoff, R.S. Mechanical properties of monolayer graphene oxide. ACS Nano 2010, 4, 6557-6564. [CrossRef] [PubMed]

22. Lee, C.; Wei, X.D.; Kysar, J.W.; Hone, J. Measurement of the elastic properties and intrinsic strength of monolayer graphene. Science 2008, 321, 385-388. [CrossRef] [PubMed]

23. Konios, D.; Stylianakis, M.M.; Stratakis, E.; Kymakis, E. Dispersion behaviour of graphene oxide and reduced graphene oxide. J. Colloid Interface Sci. 2014, 430, 108-112. [CrossRef] [PubMed]

24. Dreyer, D.R.; Park, S.; Bielawski, C.W.; Ruoff, R.S. The chemistry of graphene oxide. Chem. Soc. Rev. 2010, 39, 228-240. [CrossRef] [PubMed] 
25. Klunbud, P.; Suktha, P.; Sawangphruk, M. Decoration of graphene oxide nanosheets with amino silane-functionalized silica nanoparticles for enhancing thermal and mechanical properties of polypropylene nanocomposites. J. Appl. Polym. Sci. 2016, 133, 44382. [CrossRef]

26. Fang, M.; Wang, K.; Lu, H.; Yang, Y.; Nutt, S. Covalent polymer functionalization of graphene nanosheets and mechanical properties of composites. J. Mater. Chem. 2009, 19, 7098-7105. [CrossRef]

27. Li, P.Y.; Cheng, K.Y.; Zheng, X.C.; Liu, P.; Xu, X.J. Facile synthesis of water-soluble graphene-based composite: Non-covalently functionalized with chitosan-ionic liquid conjugation. Funct. Mater. Lett. 2016, 9, 1650045. [CrossRef]

28. Texter, J. Graphene oxide and graphene flakes as stabilizers and dispersingaids. Curr. Opin. Colloid Interface Sci. 2015, 20, 454-464. [CrossRef]

29. Wang, M.; Duan, X.; Xu, Y.; Duan, X. Functional three-dimensional graphene/polymer composites. ACS Nano 2016, 10, 7231-7247. [CrossRef] [PubMed]

30. Huh, C.D.S.; Jung, K. Polypyrrole/graphene oxide composites with improved conductivity and solubility. Conduct. Polym. 2012, 50, 10-11.

31. Wang, Y.; Shi, Z.; Fang, J.; Xu, H.; Yin, J. Graphene oxide/polybenzimidazole composites fabricated by a solvent-exchange method. Carbon 2011, 49, 1199-1207. [CrossRef]

32. Chen, H.F.; Miao, Y.; Ke, S.S. Preparation and Performance of Polypropylene/Modified Carbon Fibers by Physical Blending Method. Mater. Sci. Forum 2014, 809, 105-108. [CrossRef]

33. Xie, F.; Liu, Z.; Wei, D. Curing kinetics and properties of acrylic resin cured with aziridine crosslinker. Chin. J. Polym. Sci. 2002, 20, 65-70.

34. GB/T 23348-2009 Slow Release Fertilizer; China Standard Press: Beijing, China, 2009.

35. Shen, Y.; Du, C.W.; Zhou, J.M.; Ma, F. Application of nano Fe ${ }^{\mathrm{III}}$-tannic acid complexes in modifying aqueous acrylic latex for controlled-release coated urea. J. Agric. Food Chem. 2017, 65, 1030-1036. [CrossRef] [PubMed]

36. Spasevska, D.; Leal, G.P.; Fernández, M.; Blazevska Gilev, J.; Paulisb, M.; Tomovska, R. Crosslinked reduced graphene oxide/polymer composites via in situsynthesis by semicontinuous emulsion polymerization. RSC Adv. 2015, 5, 16414-16421. [CrossRef]

37. Satti, A.; Larpent, P.; Gun'Ko, Y. Improvement of mechanical properties of graphene oxide/poly(allylamine) composites by chemical crosslinking. Carbon 2010, 48, 3376-3381. [CrossRef]

38. Zhao, C.; Shen, Y.; Du, C.; Zhou, J.; Wang, H.; Chen, X. Evaluation of waterborne coating for controlled-release fertilizer using wurster fluidized bed. Ind. Eng. Chem. Res. 2010, 49, 9644-9647.

39. Gaur, U.; Wunderlich, B. The glass transition temperature of polyethylene. Macromolecules 1980, 13, 445-446. [CrossRef]

40. Lee, S.; Kim, Y.; Kim, D.; Ku, B.; Joh, H. Synthesis and properties of thermally reduced graphene oxide/polyacrylonitrile composites. J. Phys. Chem. Solids 2012, 73, 741-743. [CrossRef]

41. Du, C.; Zhou, G.; Wang, H.; Chen, X.; Zhou, J. Depth profiling of clay-xanthan complexes using step-scan mid-infrared photoacoustic spectroscopy. J. Soils Sedim. 2010, 10, 855-862. [CrossRef] 